\title{
The impact of the 1932 General Tariff: a difference-in-difference approach
}

\author{
Simon P. Lloyd ${ }^{1} \cdot$ Solomos Solomou ${ }^{2}$ (D)
}

Received: 28 September 2018 / Accepted: 15 February 2019 / Published online: 11 March 2019

(c) The Author(s) 2019

\begin{abstract}
We evaluate the effect of the 1932 British General Tariff on the output, labour productivity and employment growth of British industries. We provide a new disaggregated data set that matches industry-level Census of Production data with industryspecific tariff rates to accurately isolate treatment and control groups and estimate the effect of the General Tariff using difference-in-difference regressions. We evaluate a two-group comparison, between newly and non-newly protected industries, and a three-group comparison, between non-newly protected industries and newly protected industries further divided into those given a baseline $10 \%$ tariff rate and those given additional tariffs. In the two-group comparison, we identify a tariff effect that is large and statistically significant on output and productivity. In the three-group comparison, we show that the positive output and productivity effects of the tariff arise from the additional tariff protection, over and above the $10 \%$ level. These effects are observed over the periods 1930-1935 and 1930-1948, suggesting both short-run and medium-term effects on output and productivity of UK industries protected by the 1932 General Tariff.
\end{abstract}

Keywords Trade policy · General Tariff · Difference-in-difference

JEL Classification F13 · N64

Electronic supplementary material The online version of this article (https://doi.org/10.1007/s1169 8-019-00184-z) contains supplementary material, which is available to authorized users.

Solomos Solomou

ss19@cam.ac.uk

1 International Directorate, Bank of England, London, UK

2 Faculty of Economics and Peterhouse, University of Cambridge, Cambridge, UK 


\section{Introduction}

In February 1932, the UK imposed the General Tariff. This represented a $10 \%$ ad valorem tariff for British industries, although some industries received additional duties, on the recommendation of the Import Duties Advisory Committee (IDAC), whilst others were exempt or received protection during the 1920s. To evaluate the impacts of this measure, we explore the following questions: were the "newly protected" industries covered by the 1932 legislation stimulated by the tariff over the cyclical recovery of the 1930s, improving their standing relative to the non-newly protected and already protected industries; can we identify shortand medium-term effects from the General Tariff?

One of the first quantitative studies to evaluate this effect is Richardson (1967) who concluded that "the tariff had little effect on the growth of newly protected industries between 1930 and 1935". This conclusion was based on Richardson's evaluation of the effects of protection on output, employment, labour productivity and trade in the newly protected industries of 1932 relative to non-newly protected industries, comparing the benchmark years 1930 and 1935 using the Censuses of Production data. Having observed that, between 1930 and 1935, the fall in imports in newly protected industries was less than the fall in imports of other industries, Richardson argues for a non-tariff explanation for the healthy performance of the newly protected industries-recovery in the newly protected sector was thus seen as reflecting general economic recovery in the 1930s.

A major weakness in Richardson's analysis is the implicit assumption that the newly protected and other industries shared similar initial conditions in 1930. There is no attempt to compare the economic performance of the newly protected and other industries over a longer period that would allow testing of this assumption. The initial conditions in the 1920s will be unimportant only if industries were comparable in economic performance and shared similar characteristics. We know this was not the case. We apply a difference-in-difference approach, using more information about the economic performance of the two groups of industries in the pre-protection period as well as additional control variables to account for differences in the characteristics of industries over and above their growth profiles.

The difference-in-difference approach builds on Kitson and Solomou (1990) who used the data contained in the 1924, 1930 and 1935 Censuses of Production to distinguish the inter-period performance of the newly protected industries of 1932 relative to other industries, comparing the 1924-1930 and 1930-1935 periods. Thus, the inter-period difference in performance between 1924-1930 and 1930-1935 is used to identify the effects of protection on different industries. In order to test whether industry growth was stimulated by tariffs, Kitson and Solomou (1990) considered the output and productivity growth performance of the newly protected industries relative to non-newly protected industries. Output growth in the newly protected group of 1932 was stagnant in 1924-1930, whilst the non-newly protected sector saw a weighted mean growth of $2.7 \%$ per annum. However, during 1930-1935 there was a substantial turnaround as the newly 
protected group grew at $3.8 \%$ per annum, whilst the other industries grew at $2.3 \%$ per annum. Kitson and Solomou (1990, p. 111) reported a number of significance tests, suggesting that the improved output and productivity performance of the newly protected sector during the 1930 s were statistically significant, whilst there was no effect on the non-newly protected industries.

Broadberry and Crafts (2011) and Crafts (2012) were the first to estimate difference-in-difference regressions to evaluate the labour productivity effects of the General Tariff on British industries, introducing two innovations: first, the application of the difference-in-difference model adds a formal econometric panel data framework ${ }^{1}$ to the tests undertaken by Kitson and Solomou (1990); second, as noted above, the IDAC implemented a system of additional duties, in excess of $10 \%$ ad valorem, allowing us to compare three groups of industries instead of two. Broadberry and Crafts chose to compare early protected industries with the newly protected group further divided into two subgroups, the baseline group of industries given 0-10\% ad valorem tariff protection in the 1930s and those industries given additional duties on the recommendation of the IDAC. ${ }^{2}$ The Broadberry and Crafts results suggest that whilst the effect of the tariff on productivity growth is estimated to be positive, the coefficient is statistically insignificant, negating the results on labour productivity identified by Kitson and Solomou.

The current paper evaluates the Broadberry and Crafts results. Two avenues of research are pursued: first, we place the Kitson and Solomou's results within a difference-in-difference framework using the two-group comparison between the newly protected industries and the non-newly protected industries; secondly, we make the Kitson and Solomou's data set comparable to Broadberry and Crafts by distinguishing the additional duties from the baseline $10 \%$ protected industries. In constructing our data set, we identified two substantive problems with the Broadberry and Crafts's study. First, as noted above, there are problems with the implementation of the difference-in-difference method, which mean that the treatment and control groups have not been clearly distinguished. Second, a reading of the tariff regulations of the period, and the decisions on additional duties, has highlighted a significant number of classification differences with Broadberry and Crafts that affect evaluation of the General Tariff. We provide a detailed description of a new data set of the tariff protection received by each of the industries in our sample drawing upon contemporary tariff information from a variety of sources, including IDAC (1932a, b), CET (1935), NIESR (1943), Hutchinson (1965) and various HMRC reports. We present the detailed tariff classification and list of sources in Appendix A of Supplementary material to this paper as a resource for future research.

Our paper provides valuable micro-level evidence on the effects of tariffs on UK manufacturing industries in the interwar period. We find that manufacturing

\footnotetext{
1 The difference-in-difference model is now part of the standard econometrics toolkit. We provide a brief outline of the model in the Supplementary material.

${ }^{2}$ The $0-10 \%$ group is a hybrid group of newly protected (treated) and non-protected (control) industries. This grouping does not fit well in the difference-in-difference model-this is discussed further below and in the Supplementary material.
} 
industries who were protected by the General Tariff benefited in the 1930s relative to non-newly protected industries. Our results complement recent work by De Bromhead et al. (2017), who find that UK tariffs led to reduced multilateral trade in the 1930s, with a shift towards imperial imports.

Although our micro-level evidence is focused on partial equilibrium tariff effects for UK manufacturing industries and does not provide direct evidence regarding the macroeconomic effects of the tariff, our work is related to the broader literature studying the relationship between tariffs and growth from a macroeconomic perspective where diametrically opposing views on the effectiveness of trade policies are common-from both a theoretical and empirical standpoint. ${ }^{3}$ Economic theory is ambiguous about the relationship between trade policy and growth. On the one hand, tariffs can harm growth by increasing import prices, curtailing competition and preventing the exploitation of comparative advantage. On the other hand, temporary tariff protection can potentially benefit infant industries (Williamson 1990) and boost growth by aiding the discovery of dynamic comparative advantages (Rodríguez and Rodrik 2000).

Similar divergence exists in the conclusions of empirical research. For example, O'Rourke (2000) finds a significantly positive correlation between tariffs and growth in the late nineteenth century for a panel of ten countries. Using data for 22 countries over the period 1920-1940, Vamvakidis (2002) concludes that, controlling for other determinants of economic growth, tariffs provided a positive and statistically significant growth effect. Clemens and Williamson (2004) studied the interwar period within the context of the "tariff-growth paradox". They found that in the pre1914 period, tariffs were positively related to economic growth, in contrast to the post-WWII period where much of the evidence points to a negative relationship. The interwar period is then viewed as a transition period between the two regimes. Using a panel study of 35 countries over the period 1919-1938, they find there is no evidence of a statistically significant negative relationship. Focusing specifically on the 1930s, they find that the four core economies-Britain, France, Germany and the USA - benefited from significant positive tariff effects during the cyclical recovery period after 1932. In contrast, using a panel data set of 16 OECD countries, Madsen (2009) tests the relationship between trade openness (using tariff rates as a proxy variable) and economic growth, reporting a significant negative effect from tariffs on economic growth in the interwar period. The differing results suggest the presence of significant heterogeneity across countries and over time. We seek to add value to this debate by clarifying the evidence at the national level using micro-level data for UK manufacturing industries during the interwar period.

The remainder of the paper proceeds as follows: Section 2 describes our updated and extended industry-level classification of tariff rates in the 1930s. Section 3 presents the empirical strategy and results. Section 4 concludes.

\footnotetext{
${ }^{3}$ See Lampe and Sharp (2016) for a survey of the literature on the relationship between trade and growth.
} 


\section{Industry Tariff classification}

The General Tariff imposed a 10\% ad valorem tariff rate for British industries, although some industries were exempt (such as some food products and paper) and a number of industries were already protected in the 1920s. The legislation also established the Import Duties Advisory Committee (IDAC) with the powers of recommending additional duties for industries making a case in the national interest. This meant that the average tariff rate gradually moved towards the $20 \%$ level. $^{4}$

The General Tariff set out to protect most industries that were not already protected by earlier legislation. These formed the bulk of UK industries, including most textiles, clothing, iron and steel, the engineering trades and non-ferrous metals. Appendix A of Supplementary material shows that the early protected sectors were mainly covered by the McKenna Duties (1915) and the Safeguarding of Industries Act (1921). Most early protected industries were new industries, such as motor, cycle and chemicals, and formed a relatively small share of the industrial sector as a whole. However, the early protected industries were not all new industries. For example, the Silk Duties (1925) were imposed on silk and artificial silk for revenue purposes and a customs duty was imposed on hydrocarbon oils (1928).

Leak (1937) shows that by 1934 only $28.1 \%$ of imports were subject to the $10 \%$ tariff rate; most industries were given additional duties, with the modal duty being $20 \%$. Hence, the IDAC played a key role in determining UK trade policy in the 1930s. The Committee's terms of reference were to balance national interest with that of the interests of consumers and producers. The Committee saw its aim as implementing a "scientific tariff" to achieve this balance. In a study of the decisionmaking process of the IDAC, Mitchell (2005) shows that in proposing additional tariffs the IDAC considered a range of factors, including the level of import penetration, the level of efficiency in the industry, infant industry aspects, anti-dumping responses, employment effects and regional location. Importantly for our identification, Mitchell (2005) concludes that business had a limited ability to influence the setting of additional tariffs via the IDAC. In part, this was because business lobbies were poorly organised and unable to put forward a coherent case before the Committee. ${ }^{5}$ In addition, Mitchell (2005) notes that the IDAC worked to strict guidelines for the eligibility for additional tariffs. If the Committee were not convinced the criteria for additional tariffs were met, businesses could do little to convince them otherwise, and "the Committee rebuffed persistent claims" (Mitchell 2005, p. 36). Reflecting this, there was no clear relationship between industry concentration and tariff protection (Capie 1983). Industries with the most market power were not necessarily able to attain the highest rents associated with additional tariffs.

\footnotetext{
${ }^{4}$ Although non-tariff barriers, such as quotas, were being used fairly extensively by some countries during the 1930s, this was not a major feature of UK trade policy. The evidence suggests that the use of quotas was most extensive in the gold bloc economies (Irwin 2012). De Bromhead et al. (2017) show that many of the UK Quotas impacted on agricultural goods.

${ }^{5}$ Mitchell (2005) notes a handful of exceptions to this, such as the association representing the Iron and Steel industry.
} 
Here, we evaluate the broader statistical evidence on the outcomes of these policies on industry output, productivity and employment. To do this, we use industry-level data from the 1924, 1930 and 1935 Censuses of Production, considering growth rates across two time periods (1924-1930 and 1930-1935). ${ }^{6}$ We also use the data from the 1948 Census of Production to build a picture of the medium-term effects of the General Tariff by comparing the 1924-1930 and 1930-1948 periods. We classify the industries into three groups based on the tariff protection they received. The control group of non-newly protected industries is not exposed to the General Tariff in either time period. The second and third groups include newly protected industries, subject to the treatment-the 1932 General Tariff-in the second time period, but not the first. The newly protected industries are divided into: (1) industries protected at the $10 \%$ ad valorem rate and (2) industries with additional rates of protection in excess of $10 \%$. To attain accurate estimates of the differencein-difference coefficients, it is important that industries are correctly assigned to the "true" treatment and control groups. Misspecification of these groups will create bias in the OLS estimates.

There are three key refinements to our classification relative to Broadberry and Crafts (2011). First, by using all the data from the Censuses of Production, we have increased the number of industries in our sample by 19, from 90 in Broadberry and Crafts to 109 in this study. Secondly, Broadberry and Crafts have misclassified the tariff rates on a number of industries (for example, jute, bottling, seed crushing, leather tanning, leather goods, paper, fancy goods and building materials). Finally, the $0-10 \%$ classification group used by Broadberry and Crafts needs to be corrected to separate out the unprotected industries, which faced zero tariff protection (control), from industries protected at the $10 \%$ rate (treatment). The $0-10 \%$ group in Broadberry and Crafts includes 33 industries (out of their 90 industries), one-third of which should be classified as non-newly protected, potentially creating a significant bias in the identification of treatment and control groups.

\section{Empirical results}

\subsection{Two-group classification}

We follow Broadberry and Crafts (2011) in using the difference-in-difference methodology to evaluate the effects of the General Tariff. We first estimate the impact of the 1932 General Tariff using a two-group classification of industries and data for two time periods (1924-1930 and 1930-1935). This represents an extension of the Kitson and Solomou (1990) methodology to a difference-in-difference regression framework. All regressions are estimated using OLS, and robust standard errors are reported. As explained above, the control group includes the non-newly protected

\footnotetext{
6 The two time periods (1924-1930 and 1930-1935) are used because of data availability. The Censuses of Production, our source of industry-level data, were carried out in 1924, 1930 and 1935 only. Kitson and Solomou (1990) and Broadberry and Crafts (2011) use data for the same two time periods.
} 
industries, a group which includes both industries that were protected early in the 1920s and industries that did not receive protection in the interwar period. ${ }^{7}$ There are no industries in our sample that received protection prior to the 1932 General Tariff, but not after. For the two-group classification, the treatment group includes newly protected industries and does not distinguish between industries protected at the $10 \%$ rate or those with additional duties. By controlling for differences between the control and treatment groups before the policy change, the difference-in-difference regressions directly address the problems with Richardson's (1967) analysis.

The two-group difference-in-difference model is given by the following equation:

$$
\Delta y_{i, t}=\alpha_{0}+\alpha_{1} y 35_{t}+\beta \text { newpro }_{i}+\delta\left(\text { newpro }_{i} \times y 35_{t}\right)+\varepsilon_{i, t}
$$

where $i=1,2, \ldots, N$ is an index denoting the $N$ industries in our sample and $t=1,2$ is an index denoting the two time periods, 1924-1930 and 1930-1935, respectively. The dependent variable $\Delta y_{i, t}$ represents the annualised growth rate of real net output, productivity-measured as real net output per worker-or employment for industry $i$ during time period $t$. The time-invariant explanatory variable newpro ${ }_{i}$ is a dummy variable set equal to unity if industry $i$ was newly protected, and zero otherwise. The industry-invariant explanatory variable $y 35_{t}$ is a time dummy variable set equal to unity for observations in the second time period, 1930-1935, and zero otherwise.

Given these definitions, the parameters in the above equation have the following meaning. The intercept $\alpha_{0}$ captures the average annual output, productivity or employment growth of non-newly protected industries in 1924-1930. The time dummy coefficient $\alpha_{1}$ captures the average additional annual output, productivity or employment growth for non-newly protected industries in 1930-1935 in excess of their 1924-1930 growth. Therefore, the sum of $\alpha_{0}$ and $\alpha_{1}$ equals the total average annual output, productivity or employment growth for non-newly protected industries between 1930 and 1935. Similarly, the sum of $\alpha_{0}$ and $\beta$ is equal to the average annual output, productivity or employment growth for newly protected industries in 1924-1930, such that $\beta$ captures the differential growth rates of newly and nonnewly protected industries over the first time period.

The difference-in-difference coefficient $\delta$ is of principal interest, measuring the average increase in annual real output, productivity or employment growth from 1924-1930 to 1930-1935 for the newly protected industries conditional on the change in growth for the non-newly protected industries. The inclusion of the time dummy $y 35_{t}$ controls for time fixed effects-factors that are constant across industries, but vary across time, such as the prevailing macroeconomic environment-

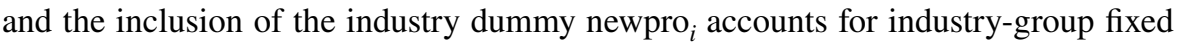
effects-factors that are constant over time, but specific to each group of industries, such as pre-tariff initial conditions for industry groups. Therefore, the differencein-difference estimator captures the treatment effect of the tariff on newly protected

\footnotetext{
7 At this stage, it should be noted that heterogeneity in our control group (i.e. including unprotected and early protected industries) poses a potential problem for the application of the difference-in-difference methodology. In Appendix B.5 of the Supplementary material, we explore the sensitivity of our results to this assumption and find that the results are robust in this dimension.
} 


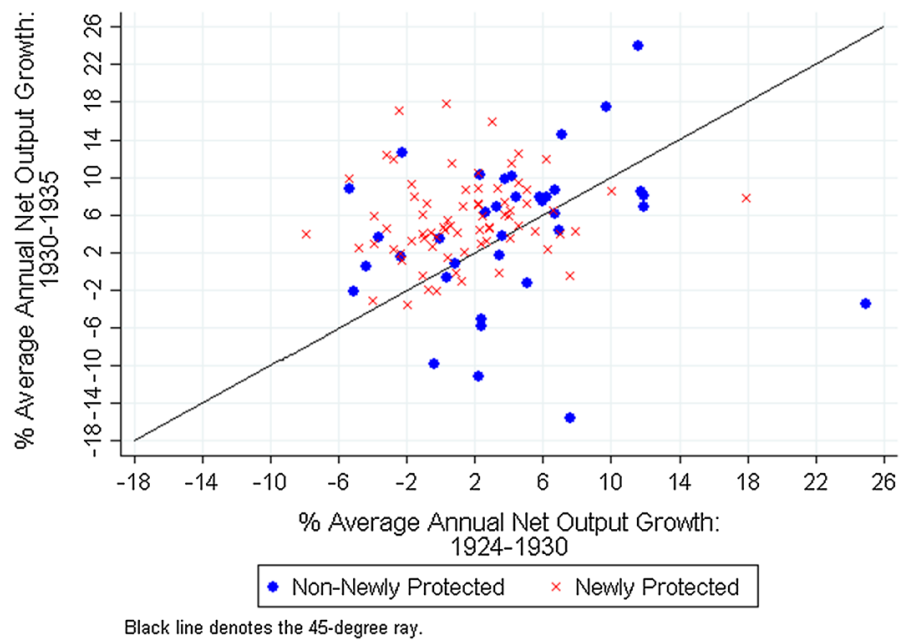

Fig. 1 Output growth across industries, 1924-1930 and 1930-1935. Note Plot of industry-by-industry annual net output growth in the two periods-1924-1930 (horizontal axis) and 1930-1935 (vertical axis). The groups are formed using the two-group classification detailed in Appendix A of Supplementary material

industries: the increase in annual output, productivity or employment growth for newly protected industries once the average growth increase in non-newly protected industries over the same period has been accounted for. This expression formalises this:

$$
\begin{aligned}
\delta_{1}= & \left(E\left[\Delta y_{i, t} \mid \text { newpro }_{i}=1, y 35_{t}=1\right]-E\left[\Delta y_{i, t} \mid \text { newpro }_{i}=1, y 35_{t}=0\right]\right) \\
& -\left(E\left[\Delta y_{i, t} \mid \text { newpro }_{i}=0, y 35_{t}=1\right]-E\left[\Delta y_{i, t} \mid \text { newpro }_{i}=0, y 35_{t}=0\right]\right)
\end{aligned}
$$

where $E$ represents the (conditional) expectations operator.

Figures 1 and 2 graphically illustrate the logic underlying the difference-in-difference methodology using the tariff classification details in Sect. 2 and Appendix A of Supplementary material. ${ }^{8}$ The plots present industry-by-industry annual growth rates of (net) output and labour productivity, respectively. In both figures, the horizontal axis plots the average annual growth rate of the variable of interest in 1924-1930, whilst the vertical axis plots the average annual growth rate in 1930-1935. The solid line depicts the $45^{\circ}$ ray of constant industry growth rates in the two periods. Observations that lie above the $45^{\circ}$ ray indicate that an industry grew faster in 1930-1935 period than in the first, and vice versa for observations that lie below. In Fig. 1, plotting annual output growth, the proportion of newly protected industries (indicated by a red cross) lying above the $45^{\circ}$ ray clearly exceeds the proportion lying below. That is, the number of newly protected industries that experienced faster annual output growth between 1930 and 1935 exceeds the number that grew faster between

\footnotetext{
${ }^{8}$ Corresponding descriptive statistics are presented in Appendix B.1 of the Supplementary material.
} 


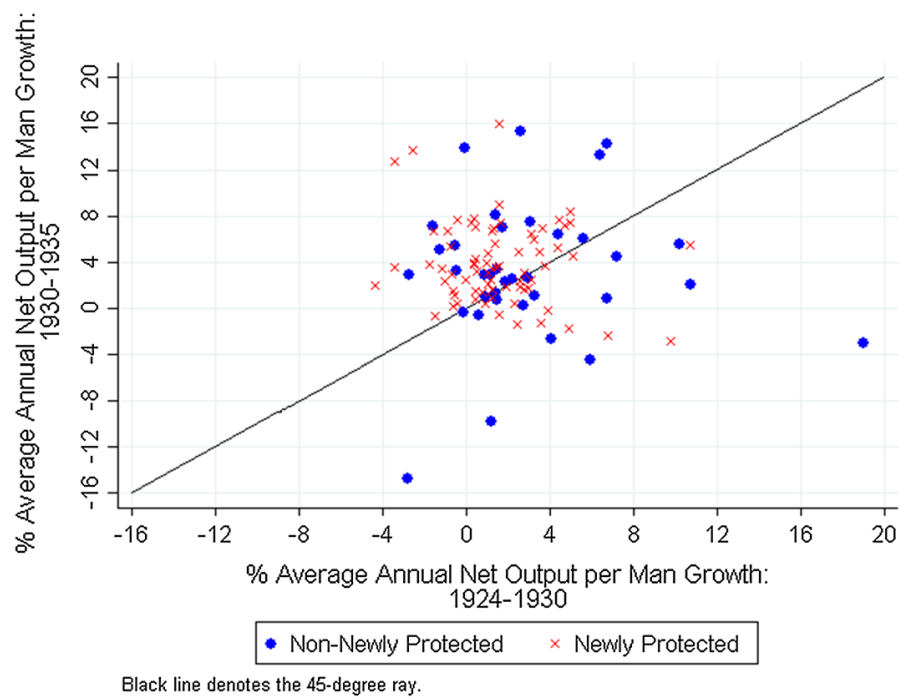

Fig. 2 Productivity growth across industries, 1924-1930 and 1930-1935. Note Plot of industry-by-industry annual net output per worker growth in the two periods-1924-1930 (horizontal axis) and 19301935 (vertical axis). The groups are formed using the two-group classification detailed in Appendix A of Supplementary material

1924 and 1930. In contrast, growth of non-newly protected industries (indicated by a blue circle) is more diverse, with many industries both above and below the $45^{\circ}$ ray. That is, relative to the non-newly protected control group, a greater proportion of newly protected treated industries grew faster in the period in which they received the treatment. Figure 2 presents the comparable industry-by-industry productivity growth figures for the same two-group classification. Although the patterns are not as stark as in Fig. 1, both figures provide illustrative evidence that the General Tariff may have had expansionary effects on treated industries during the 1930-1935 period, a result that is confirmed by the difference-in-difference regression results.

Table 1 reports formal econometric results for average annual real output, productivity and employment growth using the two-group classification, confirming the visual inspection of Figs. 1 and 2. In column (1), we estimate that the average annual output growth for non-newly protected industries in 1930-1935 was not significantly different to 1924-1930. The results highlight the importance of accounting for initial conditions; we find that between 1924 and 1930 the average annual output growth for newly protected industries was 2.82 percentage points lower than for the non-newly protected industries over the same period, significant at the $5 \%$ level. Notably, the difference-in-difference coefficient indicates that the tariff had an expansionary treatment effect of 4.07 percentage points per annum on treated industries, significant at the 5\% level. The size of this treatment effect more than offset the output growth shortfall of newly protected industries in 1924-1930.

In column (2), we estimate that the tariff also had an expansionary effect on the labour productivity growth of newly protected industries. In 1924-1930, the productivity of non-newly protected industries grew a $3.01 \%$ per annum, a figure that did 
Table 1 Difference-in-difference results for the two-group classification

(1) (2)

Net output growth Net output per worker growth
(3)

Employment growth

\begin{tabular}{llll}
\hline D-in-D for newly protected industries, $\widehat{\delta}$ & $\begin{array}{l}4.066^{* *} \\
(1.783)\end{array}$ & $\begin{array}{l}2.161^{*} \\
(1.131)\end{array}$ & $\begin{array}{l}1.841 \\
(1.124)\end{array}$ \\
Dummy variable for newly protected indus- & $-2.822^{* *}$ & $-1.459^{*}$ & $-1.298^{*}$ \\
tries, $\widehat{\beta}$ & $(1.087)$ & $(0.800)$ & $(0.698)$ \\
Dummy variable for 1930-1935, $\widehat{\alpha}_{1}$ & 0.064 & 0.131 & -0.056 \\
& $(1.641)$ & $(0.925)$ & $(0.981)$ \\
Constant, $\widehat{\alpha}_{0}$ & $4.221^{* * *}$ & $3.013^{* * *}$ & $1.158^{* *}$ \\
& $(0.982)$ & $(0.654)$ & $(0.580)$ \\
Observations & 218 & 218 & 218 \\
$R^{2}$ & 0.098 & 0.057 & 0.042 \\
\hline
\end{tabular}

Estimated regression results for the two-group classification. In column (1), the dependent variable is annualised average (real) net output growth (in annualised percentage points). The corresponding dependent variables in columns (2) and (3) are annualised average net output per worker growth and employment growth, respectively. All regressions are estimated by OLS and robust standard errors are reported, where $* * * p<0.01 ; * * p<0.05 ; * p<0.1$

not significantly change in 1930-1935. Productivity growth of the newly protected industries was 1.46 percentage points per annum less than their non-newly protected counterparts in 1924-1930. The difference-in-difference coefficient indicates that, between 1930 and 1935, the tariff had an expansionary impact on productivity growth of 2.16 percentage points per annum, more than reversing the relative productivity growth shortfall in the earlier period, significant at the $10 \%$ significance level.

In column (3), we estimate the two-group classification with annual employment growth as the dependent variable. We do not find that the General Tariff had a significant treatment effect on the employment growth of newly protected industries in 1930-1935.

Taken together, the differing significance of treatment effects for productivity and employment growth identified in columns (2) and (3) indicates that the net output of newly protected industries predominantly increased because of productivity improvements rather than shifts in employment demand/supply.

\subsection{Three-group classification}

The three-group classification allows for a more detailed examination of the effects of differing tariff protection rates. As in the two-group analysis, our control group includes industries that were both early protected and zero-protected. ${ }^{9}$ For our baseline three-group classification, we separate the newly protected industries into two treated subgroups: (1) newly protected industries at the $10 \%$ ad valorem rate and (2)

\footnotetext{
9 We show that our results are robust when the control group is varied to contain only unprotected industries and only early protected industries in turn in Appendix B.5 of the Supplementary material.
} 


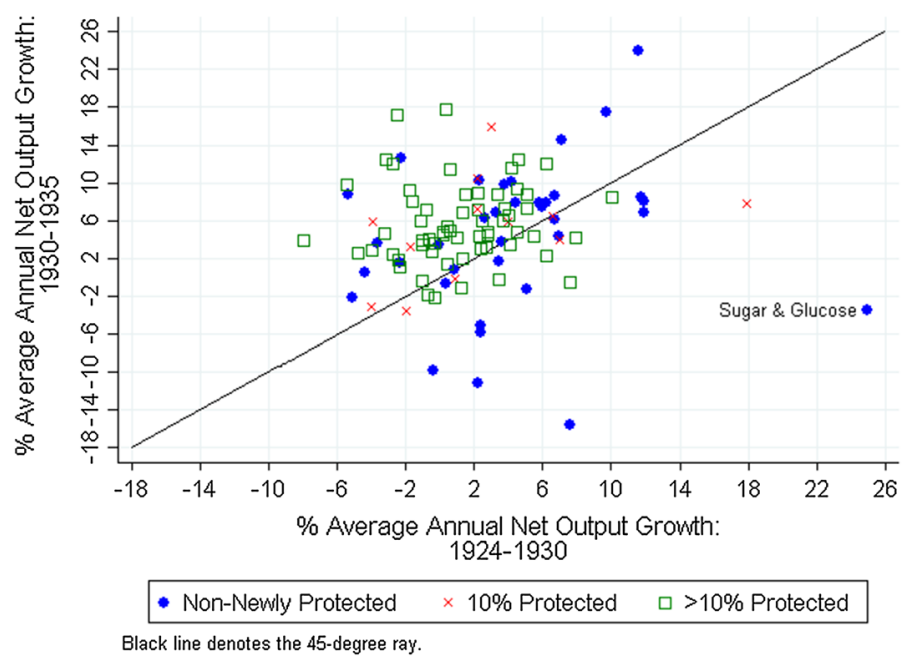

Fig. 3 Output growth across industries, 1924-1930 and 1930-1935. Note Plot of industry-by-industry annual net output growth in the two periods-1924-1930 (horizontal axis) and 1930-1935 (vertical axis). The groups-non-newly, $10 \%$ and additionally protected-are formed using the three-group classification detailed in Appendix A of Supplementary material

newly protected industries with tariffs at additional rates in excess of $10 \%$ ad valorem. The three-group model can be specified as:

$$
\Delta y_{i, t}=\alpha_{0}+\alpha_{1} y 35_{t}+\beta_{\text {ten }} \operatorname{ten}_{i}+\beta_{\text {add }} \operatorname{add}_{i}+\delta_{\text {ten }}\left(\operatorname{ten}_{i} \times y 35_{t}\right)+\delta_{\text {add }}\left(\operatorname{add}_{i} \times y 35_{t}\right)+\varepsilon_{i, t}
$$

where the two time periods, the dependent variable $\Delta y_{i, t}$ and the time dummy $y 35_{t}$, are defined analogously to the two-group classification. The time-invariant explanatory variables ten ${ }_{i}$ and $\operatorname{add}_{i}$ are dummy variables set equal to unity if industry $i$ was newly protected at the $10 \%$ rate or at an additional rate, respectively (and zero otherwise). Thus, the coefficients $\delta_{\text {ten }}$ and $\delta_{\text {add }}$ are the difference-in-difference estimators for the $10 \%$ and additionally protected industries, respectively, representing the average effect of the tariff on each subgroup of newly protected industries relative to all non-newly protected industries. The parameters are defined as:

$$
\begin{aligned}
\delta_{\text {ten }}= & \left(E\left[\Delta y_{i, t} \mid \operatorname{ten}_{i}=1, \operatorname{add}_{i}=0, y 35_{t}=1\right]-E\left[\Delta y_{i, t} \mid \operatorname{ten}_{i}=1, \operatorname{add}_{i}=0, y 35_{t}=0\right]\right) \\
& -\left(E\left[\Delta y_{i, t} \mid \operatorname{ten}_{i}=0, \operatorname{add}_{i}=0, y 35_{t}=1\right]-E\left[\Delta y_{i, t} \mid \operatorname{ten}_{i}=0, \operatorname{add}_{i}=0, y 35_{t}=0\right]\right) \\
\delta_{\text {add }}= & \left(E\left[\Delta y_{i, t} \mid \operatorname{ten}_{i}=0, \operatorname{add}_{i}=1, y 35_{t}=1\right]-E\left[\Delta y_{i, t} \mid \operatorname{ten}_{i}=0, \operatorname{add}_{i}=1, y 35_{t}=0\right]\right) \\
& -\left(E\left[\Delta y_{i, t} \mid \operatorname{ten}_{i}=0, \operatorname{add}_{i}=0, y 35_{t}=1\right]-E\left[\Delta y_{i, t} \mid \operatorname{ten}_{i}=0, \operatorname{add}_{i}=0, y 35_{t}=0\right]\right)
\end{aligned}
$$

Like Figs. 1 and 2 for the two-group classification, Figs. 3 and 4 visually illustrate the logic of our three-group classification. ${ }^{10}$ In Fig. 3, plotting annual output growth, the proportion of newly protected industries, both at the $10 \%$ rate (indicated by a

$\overline{10}$ Corresponding descriptive statistics are presented in Appendix B.1 of the Supplementary material. 


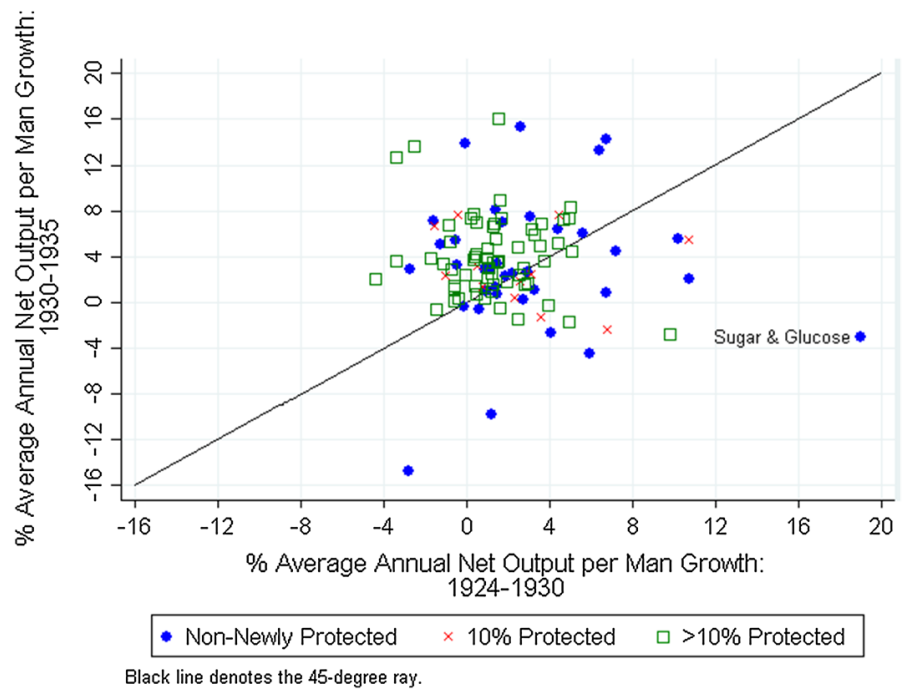

Fig. 4 Productivity growth across industries, 1924-1930 and 1930-1935. Note Plot of industry-by-industry annual net output per worker growth in the two periods-1924-1930 (horizontal axis) and 19301935 (vertical axis). The groups-non-newly, 10\% and additionally protected-are formed using the three-group classification detailed in Appendix A of Supplementary material of this paper

red cross) and additional rates (indicated by a green square), lying above the $45^{\circ}$ ray clearly exceeds the proportion lying below. That is, the number of newly protected industries that experienced faster annual output growth between 1930 and 1935, the period in which they received the tariff treatment, exceeds the number that grew faster between 1924 and 1930. In contrast, the growth of non-newly protected industries (indicated by a blue circle) is more varied, with numerous observations above and below the $45^{\circ}$ ray.

Figure 4 presents the comparable productivity growth figures for the three-group classification. Again, a large fraction of newly protected industries-especially those protected with additional rates-lie above the $45^{\circ}$ ray, indicating that the General Tariff had expansionary effects on treated industries during the 1930-1935 period. ${ }^{11}$

The regression results, reported in Table 2, confirm the insights from visual inspection of Figs. 3 and 4 for the three-group classification. Panels A, B and C present the results for the regressions with real output growth, productivity growth and employment growth as the dependent variables, respectively. The baseline results for the three-group classification are in column (1) of each panel. Columns (2)-(5) report regression results with additional control variables included to account for

\footnotetext{
11 In Figs. 3 and 4, we label "Sugar and Glucose" to emphasise that they may potentially act as outliers in our econometric setup. We present formal analysis in Appendix B.7 of Supplementary material to reflect this. Importantly, our headline results are robust to the removal of Sugar and Glucose from our sample. Appendix B.8 of Supplementary material also shows that our headline results are robust to the weighting of industries by their size.
} 


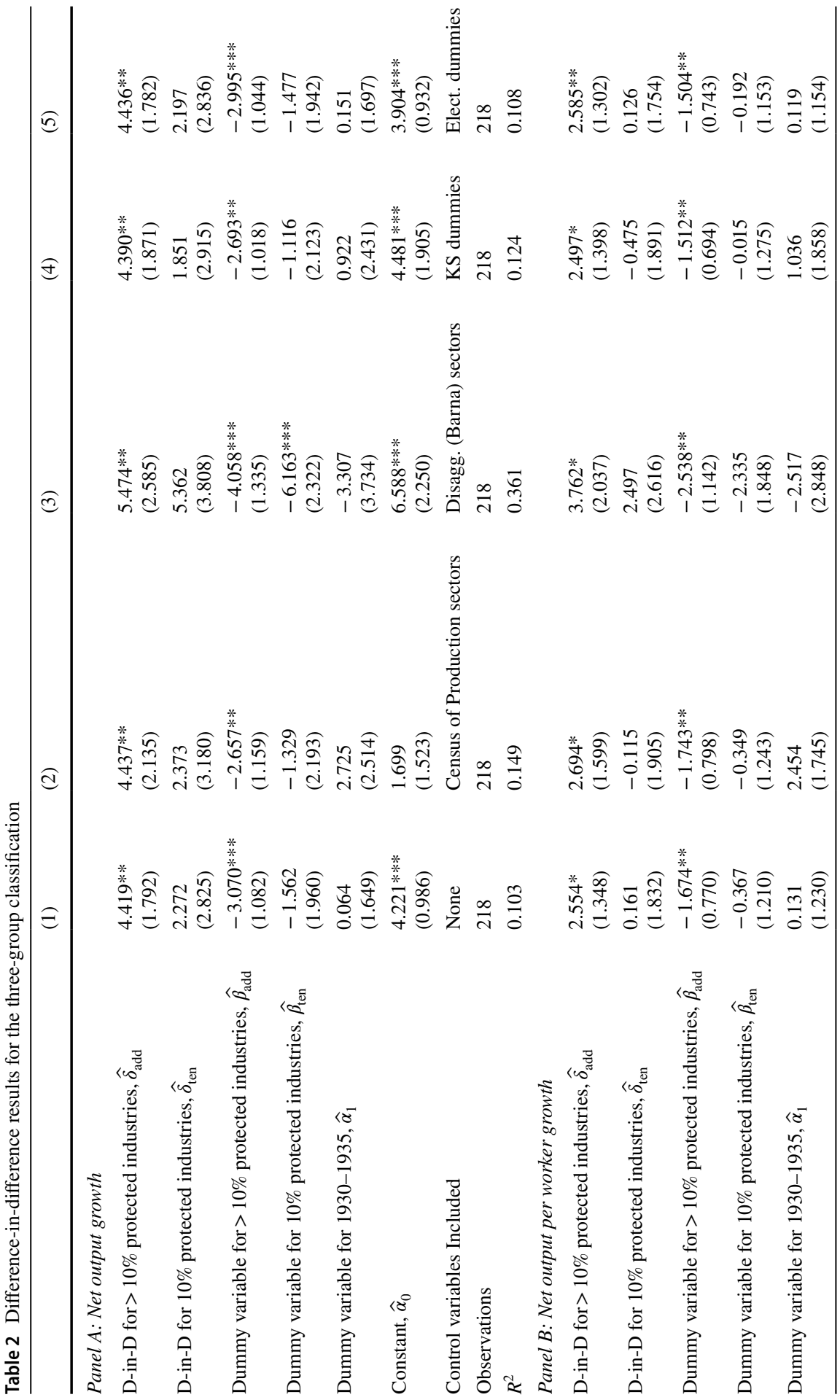




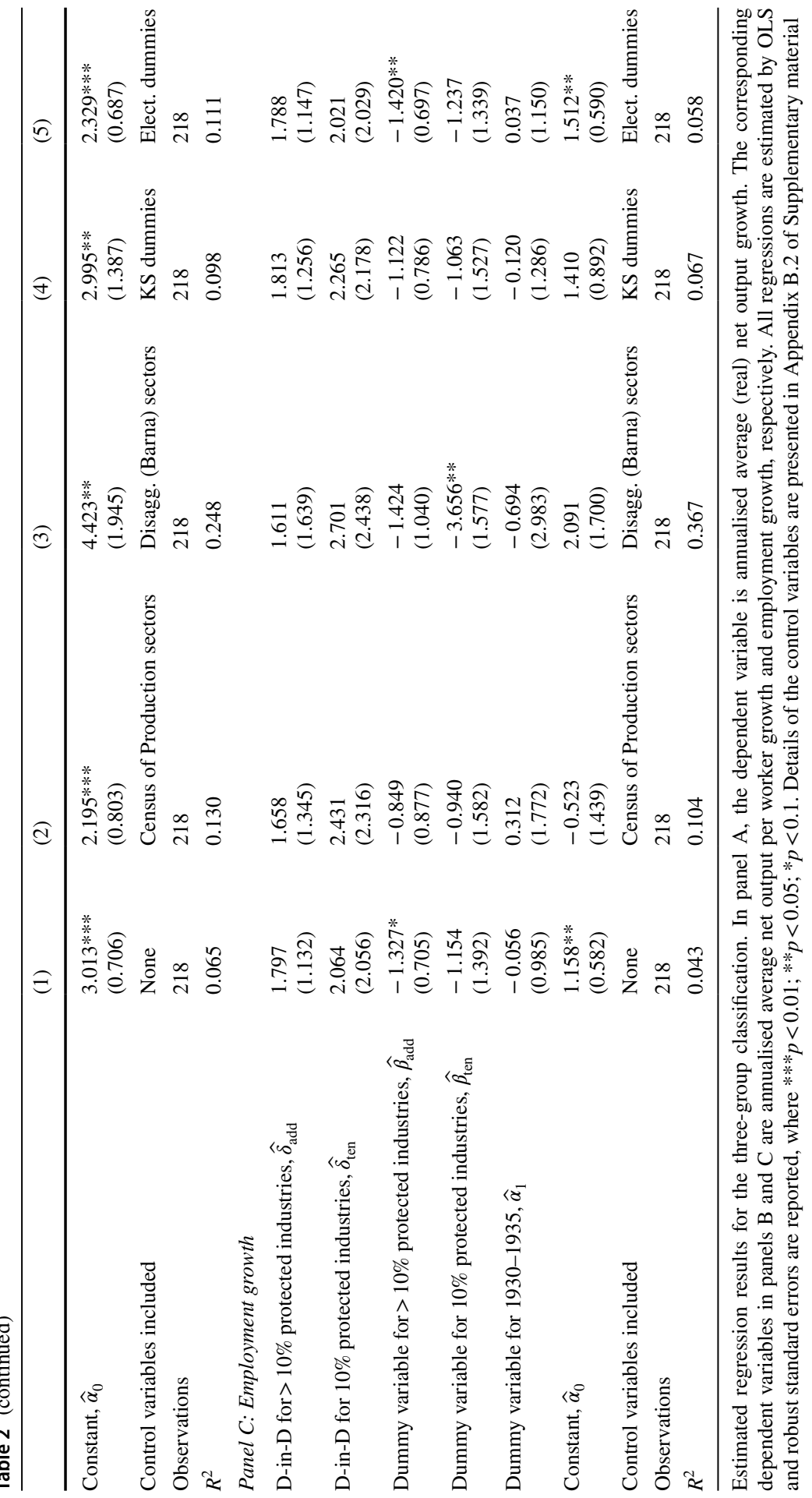


potential differences in industry characteristics over and above their interwar growth profile. (These controls are explained further below and in Appendix B.2 of Supplementary material. $)^{12}$

In column (1), we find that average real output growth for non-newly protected industries was $4.22 \%$ in 1924-1930. This figure did not change significantly in 1930-1935. In 1924-1930, industries that received a 10\% tariff rate in 1932 grew more slowly than non-newly protected industries, by 1.56 percentage points per annum. The tariff did have a positive effect on these industries $(2.27$ percentage points per annum), but both these effects are statistically insignificant. In contrast, the output effect of the tariff on additionally protected industries is statistically significant and positive. In particular, the additionally protected industries grew at 3.07 percentage points per annum less than non-newly protected industries in 1924-1930. This growth loss is more than reversed in 1930-1935, as the relevant difference-indifference coefficient indicated that the treatment effects of the tariff on these industries were 4.42 percentage points per annum, significant at the 5\% level.

We also find that the tariff had a positive treatment effect on the productivity of additionally protected industries in 1930-1935, significant at the $10 \%$ level. The productivity of additionally protected industries grew at 1.67 percentage points per annum less than non-newly protected industries in 1924-1930, a growth loss that is more than reversed in 1930-1935. The treatment effect for 1930-1935 is estimated to be 2.55 percentage points per annum for additionally protected industries, relative to non-newly protected industries. For comparison, using their classification, Broadberry and Crafts (2011) estimate that additionally protected industries growth was 2.3 percentage points per annum higher than the growth of early protected industries, although their estimate is statistically insignificant. The tariff effect on the productivity of $10 \%$ protected industries is positive, but not statistically significant.

As with the two-group classification, we find that the tariff did not have a significant effect on the employment growth rates of either the $10 \%$ or additional rate industries. As in the two-group classification, this indicates that the tariff predominantly boosted the output of UK manufacturing industries through productivity improvements, rather than through labour market mechanisms.

In columns (2)-(5) of Table 2, we report the results with additional controls included in the regression. These controls are intended to capture otherwise unobserved features of industries that may simultaneously be correlated with the tariff treatment and their output, productivity or employment growth. That is, they are intended to capture industry features that may have caused differential changes in growth rates across industry groups absent the General Tariff, which, if unaccounted for, might bias estimates of the difference-in-difference coefficients.

Because data constraints limit the possible control variables, all controls are time invariant and are included in the regression alongside an interaction with the time dummy $y 35_{t}$. When augmented with additional industry-specific control variables $\boldsymbol{X}_{i}$, the regression framework has the following form:

\footnotetext{
${ }^{12}$ We present similar robustness exercises for the two-group classification in Appendix B.3 of the Supplementary material.
} 


$$
\begin{aligned}
\Delta y_{i, t}= & \alpha_{0}+\alpha_{1} y 35_{t}+\beta_{\text {ten }} \operatorname{ten}_{i}+\beta_{\text {add }} \operatorname{add}_{i}+\delta_{\text {ten }}\left(\operatorname{ten}_{i} \times y 35_{t}\right)+\delta_{\text {add }}\left(\operatorname{add}_{i} \times y 35_{t}\right) \\
& +\gamma_{1} \boldsymbol{X}_{i}+\gamma_{2}\left(\boldsymbol{X}_{i} \times y 35_{t}\right)+\varepsilon_{i, t}
\end{aligned}
$$

The regression results with control variables included serve to reinforce our main conclusion: industries that received additional protection under the 1932 General Tariff received a significant output and productivity benefit relative to the control group.

In column (2), we report the regression results with a set of control variables for the 13 different sectors as defined by the Census of Production. That is, we have a dummy variable for each sector of the economy that is set to unity if that industry is classed within that sector according to the Census of Production, and zero otherwise. To the extent that industries within the same sector may co-move, but differ from other sectors, or be subject to similar tariff protection within sectors, this control variable can capture time-varying, industry-specific influences, as well as potential nonrandom tariff assignment. Column (2) illustrates that the tariff effects for additionally protected industries for net output growth and net output per worker growth are robust to the inclusion of controls for industry-sector groups. The Census of Production sector dummies capture limited sectoral heterogeneity. There may still be heterogeneity of industries within each sector which could better be accounted for. In column (3), we report the results using a more disaggregated classification from Barna (1952) with 29 sectors. The results in column (3) indicate that the tariff effects for additionally protected industries are robust to these time-varying controls.

In addition to sector dummies, columns (4) and (5) present regression results with additional control variables to account for specific features of industries, which may simultaneously be correlated with the growth of an industry as well as the tariff protection they received. In column (4), we use control variables from Kitson and Solomou (1990), which classify industries as resource intensive, labour intensive, scale intensive, an industry with differentiated products, or a food, drink and tobacco industry. Similarly, in column (5), we define control variables for industries that were more or less intensively using electricity as an input to production. Importantly, the headline results are robust to the inclusion of these control variables. Again, these control variables are intended to capture industry features that may have led to differences in their evolution absent the General Tariff.

Additionally, Appendix B.7 of Supplementary material presents a robustness exercise which accounts for industries whose output and employment growth over the 1924-1935 period could be considered as potential outliers. These robustness regressions can be interpreted as difference-in-difference regressions with a larger "region of common support" between treatment and control variables (Ravallion 2008). Importantly, our headline results are robust to the omission of outliers. 
Table 3 Difference-in-difference results for the three-group classification for 1924-1930 and 1930-1948

(1) (2) (3)

Net output growth Net output per Employment growth worker growth

\begin{tabular}{|c|c|c|c|}
\hline D-in-D for $>10 \%$ protected industries, $\widehat{\delta}_{\text {add }}$ & $\begin{array}{l}3.118 * * \\
(1.317)\end{array}$ & $\begin{array}{l}1.838 * * \\
(0.879)\end{array}$ & $\begin{array}{l}1.190 \\
(0.946)\end{array}$ \\
\hline D-in-D for $10 \%$ protected industries, $\widehat{\delta}_{\text {ten }}$ & $\begin{array}{l}1.887 \\
(2.496)\end{array}$ & $\begin{array}{l}0.950 \\
(1.437)\end{array}$ & $\begin{array}{l}0.882 \\
(1.977)\end{array}$ \\
\hline $\begin{array}{l}\text { Dummy variable for }>10 \% \text { protected indus- } \\
\text { tries, } \widehat{\beta}_{\text {add }}\end{array}$ & $\begin{array}{l}-3.083^{* * *} \\
(1.140)\end{array}$ & $\begin{array}{l}-1.744 * * * \\
(0.792)\end{array}$ & $\begin{array}{l}-1.264^{*} \\
(0.732)\end{array}$ \\
\hline $\begin{array}{l}\text { Dummy variable for } 10 \% \text { protected indus- } \\
\text { tries, } \widehat{\beta}_{\text {ten }}\end{array}$ & $\begin{array}{l}-1.902 \\
(2.089)\end{array}$ & $\begin{array}{l}-0.501 \\
(1.294)\end{array}$ & $\begin{array}{l}-1.345 \\
(1.472)\end{array}$ \\
\hline Dummy variable for $1930-1948, \widehat{\alpha}_{1}$ & $\begin{array}{l}-1.598 \\
(1.174)\end{array}$ & $\begin{array}{l}-1.785^{* * * *} \\
(0.797)\end{array}$ & $\begin{array}{l}0.240 \\
(0.791)\end{array}$ \\
\hline Constant, $\widehat{\alpha}_{0}$ & $\begin{array}{l}4.206^{* * * *} \\
(1.041)\end{array}$ & $\begin{array}{l}3.107 * * * \\
(0.723)\end{array}$ & $\begin{array}{l}1.043 * \\
(0.605)\end{array}$ \\
\hline Observations & 206 & 206 & 206 \\
\hline$R^{2}$ & 0.060 & 0.065 & 0.044 \\
\hline
\end{tabular}

Estimated regression results for the three-group classification. In column (1), the dependent variable is annualised average (real) net output growth. The corresponding dependent variables in columns (2) and (3) are annualised average net output per worker growth and employment growth, respectively. All regressions are estimated by OLS and robust standard errors are reported, where $* * * p<0.01 ; * * p<0.05$; $* p<0.1$

\subsection{Medium-Term Effects of the General Tariff}

The previous results suggest a positive short-term output and productivity effect arising from the General Tariff during the period 1930-1935. Extending the Census of Production data to include the 1948 Census allows us to investigate whether the expansionary effects of the tariff persisted over time. To investigate the mediumterm time profile of the effect, we combine industry-level output and employment data from the 1948 Census of Production, with our existing data from the 1924, 1930 and 1935 censuses. Of the 109 industries in our baseline sample for the 1924-1935 period, 103 remain in the 1948 sample. ${ }^{13}$ We estimate the effect of the tariff using the three-group classification, redefining the second period in the sample as the 1930-1948 period (instead of 1930-1935). The dependent variables remain the average annual growth of real output, productivity and employment over each period.

Table 3 indicates that the 1932 General Tariff had medium-term expansionary effects for additionally protected industries. ${ }^{14}$ Column (1) illustrates that the tariff treatment effect for the output growth of additionally protected industries was $3.12 \%$ per annum, a result that is significant at the $5 \%$ significance level. The

\footnotetext{
13 The descriptive statistics for the period 1930-1948 are provided in Appendix B.1 of the Supplementary material, where the distribution of industries across tariff groups is also provided.

${ }^{14}$ We report robustness exercises for this regression in Appendix B.4 of the Supplementary material, showing that this result is robust to the inclusion of controls.
} 
corresponding treatment effect of productivity of $1.84 \%$ per annum, in column (2), is also significant at the $5 \%$ level. As expected, the magnitude of these effects is slightly smaller than the short-term effects reported in Table 2, but they remain large and significant.

\section{Conclusions}

The application of the difference-in-difference model to the analysis of the policy impact of the General Tariff on British industry has provided new insights. Refining the tariff classification into three groups adds value to the analysis of UK tariffs during the 1930s, allowing us to distinguish between the $10 \%$ tariff rate and additional tariff rates. This three-group comparison clearly suggests that the treatment effect of the General Tariff was large and statistically significant only for the additionally protected industries. This effect is identified over the short run when we consider the inter-period comparisons between 1924-1930 and 1930-1935, but a similar effect is also identified over the medium term when we consider the inter-period comparisons between 1924-1930 and 1930-1948. The Import Duties Advisory Committee (IDAC) viewed additional tariff rates as a mechanism for helping industries to restructure to help them compete during the 1930s. The positive output and productivity effects that we identify suggest that they were effective in achieving some of their aims.

The results reported in this study show that tariffs can have positive effects under specific circumstances. This UK-interwar case study should be viewed against the backdrop of a global depression, a unique British position of unilateral free trade and a tariff policy that targeted particular industries via the role of the IDAC. Using industry-level data, we identify that some benefits for the relative output and productivity growth of newly protected industries did arise under these specific circumstances. Given that the newly protected sector formed a very large proportion of the UK industrial output, this is likely to result in positive effects on the UK industrial sector.

This study has used disaggregated-level data to analyse the effects of tariffs on British industries during the 1930s. Although there have been attempts to relate industry-level tariffs and economic growth at the aggregate level, such results cannot be mechanically applied to the interwar period. For example, Lehmann and O'Rourke (2011) used a panel data set for 10 countries over the period 1870-1914 and found a positive relationship between industry tariffs and economic growth; however, they also argue that this relationship is likely to change over time.

Acknowledgements We thank the editor and anonymous referees for useful comments. The majority of this paper was written whilst Lloyd was a member of Gonville \& Caius College, University of Cambridge. The views expressed here are those of the authors and do not reflect the position of the Bank of England or its Committees. 
Open Access This article is distributed under the terms of the Creative Commons Attribution 4.0 International License (http://creativecommons.org/licenses/by/4.0/), which permits unrestricted use, distribution, and reproduction in any medium, provided you give appropriate credit to the original author(s) and the source, provide a link to the Creative Commons license, and indicate if changes were made.

\section{References}

Barna T (1952) The interdependence of the British Economy. J R Stat Soc Ser A (Gen) 115(1):29-77

Broadberry SN, Crafts NFR (2011) “Openness, protectionism and Britain's productivity performance over the long-run. In: Wood GE, Mills T, Crafts N (eds) Monetary and banking history: essays in honour of Forrest Capie. Routledge, Abingdon

Capie F (1983) Depression and protectionism: Britain between the wars. Allen \& Unwin, Boston

Clemens MA, Williamson JG (2004) Why did the Tariff-growth correlation change after 1950? J Econ Growth 9(1):5-46

Crafts NFR (2012) British relative economic decline revisited: the role of competition. Explor Econ Hist 49(1):17-29

De Bromhead A, Fernihough A, Lampe M, O'Rourke KH (2017) When Britain turned inward: protection and the shift towards Empire in interwar Britain. Working Paper No. 23164, National Bureau of Economic Research. Forthcoming American Economic Review

Irwin DA (2012) Trade policy disaster: lessons from the 1930s. MIT Press, Cambridge

Kitson M, Solomou SN (1990) Protectionism and economic revival: the British Interwar Economy. Cambridge University Press, Cambridge

Lampe M, Sharp P (2016) Cliometric approaches to international trade. In: Diebolt C, Haupert M (eds) Handbook of cliometrics. Springer, Berlin, pp 295-330

Leak H (1937) Some results of the Import Duties Act. J R Stat Soc 100(4):558-606

Lehmann SH, O'Rourke KH (2011) The structure of protection and growth in the late nineteenth century. Rev Econ Stat 93(2):606-616

Madsen JB (2009) Trade barriers, openness, and economic growth. South Econ J 76(2):397-418

Mitchell N (2005) Public and private interests in the formulation of government policy: the case of the Import Duties Advisory Committee [IDAC] in 1930s Britain, London School of Economics, Ph.D. thesis. http://etheses.1se.ac.uk/1829/1/U202398.pdf. Accessed Feb 2019

O'Rourke KH (2000) Tariffs and growth in the late 19th century. Econ J 110(463):456-483

Ravallion M (2008) Evaluating anti-poverty programs. In: Schultz TP, Strauss J (eds) Handbook of development economics. Elsevier, Amsterdam

Richardson HW (1967) Economic recovery in Britain, 1932-9. Weidenfeld and Nicolson, London

Rodríguez F, Rodrik D (2000) Trade policy and economic growth: a sceptic's guide to cross-national evidence. NBER Macroecon Annu 15:261-325

Vamvakidis A (2002) How robust is the growth-openness connection? Historical evidence. J Econ Growth 7(1):57-80

Williamson JG (1990) Latin American adjustment: how much has happened?. Peterson Institute for International Economics, Washington

\section{Tariff Rate Classification Sources}

CET (1935) Customs and Excise Tariff of the United Kingdom of Great Britain and Northern Ireland in operation on the 1st January, 1935. Published under the authority of the Commissioners of His Majesty's Customs and Excise, H.M. Stationary Office

Cmd. 5296 (1936) Twenty-seventh report of the commissioners of His Majesty's customs and excise for the year ended 31st March 1936 being the 80th report relating to the customs and the 79th report relating to the excise. HMSO

Hutchinson HJ (1965) Tariff-making and industrial reconstruction: an account of the work of the Import Duties Advisory Committee 1932-39. Harrap, London 
IDAC (1932a) Import duties: report by the Import Duties Advisory Committee and additional import duties (No. 1) Order, Import Duties Advisory Committee

IDAC (1932b) Statutory rules and orders: customs: additional import duties, No. 257, Import Duties Advisory Committee

NIESR (1943) Trade regulations and commercial policy of the United Kingdom. National Institute of Economic and Social Research, Cambridge University Press, Cambridge

\section{Disaggregated Industry Data}

Board of Trade: Business Statistics Office, Census of Production: Final Report (Censuses, 1924, 1930, 1935 and 1948). HMSO, London

Bowley AS (1944) Studies in the national income: 1924-1938. Cambridge University Press, Cambridge

Brown EC (1954) Industrial production in 1935 and 1948. London and Cambridge Economic Bulletin, December, pp v-vii

Schwartz GL, Rhodes EC, Output, employment and wages in the United Kingdom: 1924, 1930, 1935. London and Cambridge Economic Service, Royal Economic Society Memorandum, No. 75

Publisher's Note Springer Nature remains neutral with regard to jurisdictional claims in published maps and institutional affiliations. 